PROGRESS REPORT

of

\title{
Experimental Studies of the Structure of Grain Boundaries
}

Grant No. DE-FG02-85ER45211

Submitted to

Department of Energy

April 1993

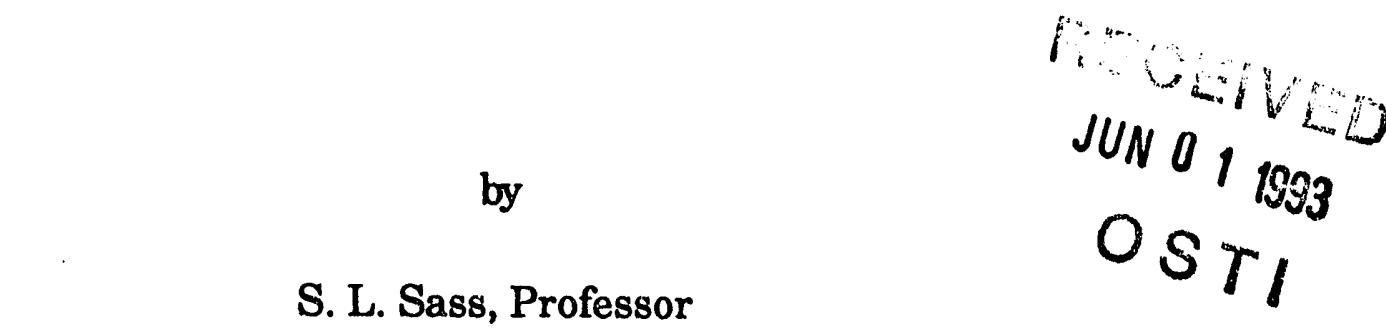

Department of Materials Science and Engineering Cornell University

\section{DISCLAIMER}

This report was prepared as an account of work sponsored by an agency of the United States Government. Neither the United States Government nor any agency thereof, nor any of their employees, makes any warranty, express or implied, or assumes any legal liability or responsibility for the accuracy, completeness, or usefulness of any information, apparatus, product, or process disclosed, or represents that its use would not infringe privately owned rights. Reference herein to any specific commercial product, process, or service by trade name, trademark, manufacturer, or otherwise does not necessarily constitute or imply its endorsement, recommendation, or favoring by the United States Government or any agency thereof. The views and opinions of authors expressed herein do not necessarily state or reflect those of the United States Government or any agency thereof. 


\section{Research Highlights}

The long range goals of this research project are to understand the factors that influence the structure and properties of grain boundaries in intermetallic compounds, to understand how solute segregation influences grain boundary structure and causes boundaries to become embrittled in Fe-base alloys, and to explore methods for controlling grain boundary properties. In the following write-up the research highlights of the past year will be discussed.

\section{A. The Structure of Grain Boundaries in Intermetallic Compounds}

Previous work on this grant has focussed on exploring the influence of boron additions on the structure of grain boundaries in $\mathrm{Ni}_{3} \mathrm{Al}$, with the results published in references 1 and 2. One of the conclusions of this work was that the antiphase boundary (APB) energy measured for dislocations which dissociate in grain boundaries is much smaller than for similar dislocations in the bulk. For small angle [001] twist boundaries with misorientation angles, $\theta$, above $1.6^{\circ}$, in the presence of boron, the APB energy approached zero. Unfortunately, only a few experimental observations were reported in ref. (2) and so additional work was begun to check this result. Fig. 1 shows recent observations on a dissociated small angle boundary where paired partial dislocations with Burgers vectors of the type $a / 2<110>$ are clearly present. Table 1 summarizes all of our past and present measurements of APB energy. It can be seen that the APB energy decreases with increasing $\theta$, when boron is present. Because of the limited number of observations on the boron-free material, it is not yet possible to discern any trend and work is continuing.

To explore the influence of crystal structure type on grain boundary structure in intermetallic compounds, research was begun on $\mathrm{NiAl}$, with material provided by R. Darolia of General Electric Aircraft Engines. Figure 2 shows a recent observation on a small angle tilt boundary in $\mathrm{NiAl}$ containing 300 wppm B. Both 


\section{$\mathrm{Ni} 3 \mathrm{Al}+500$ wppm B}

\section{Small Angle [001] Twist Boundary}
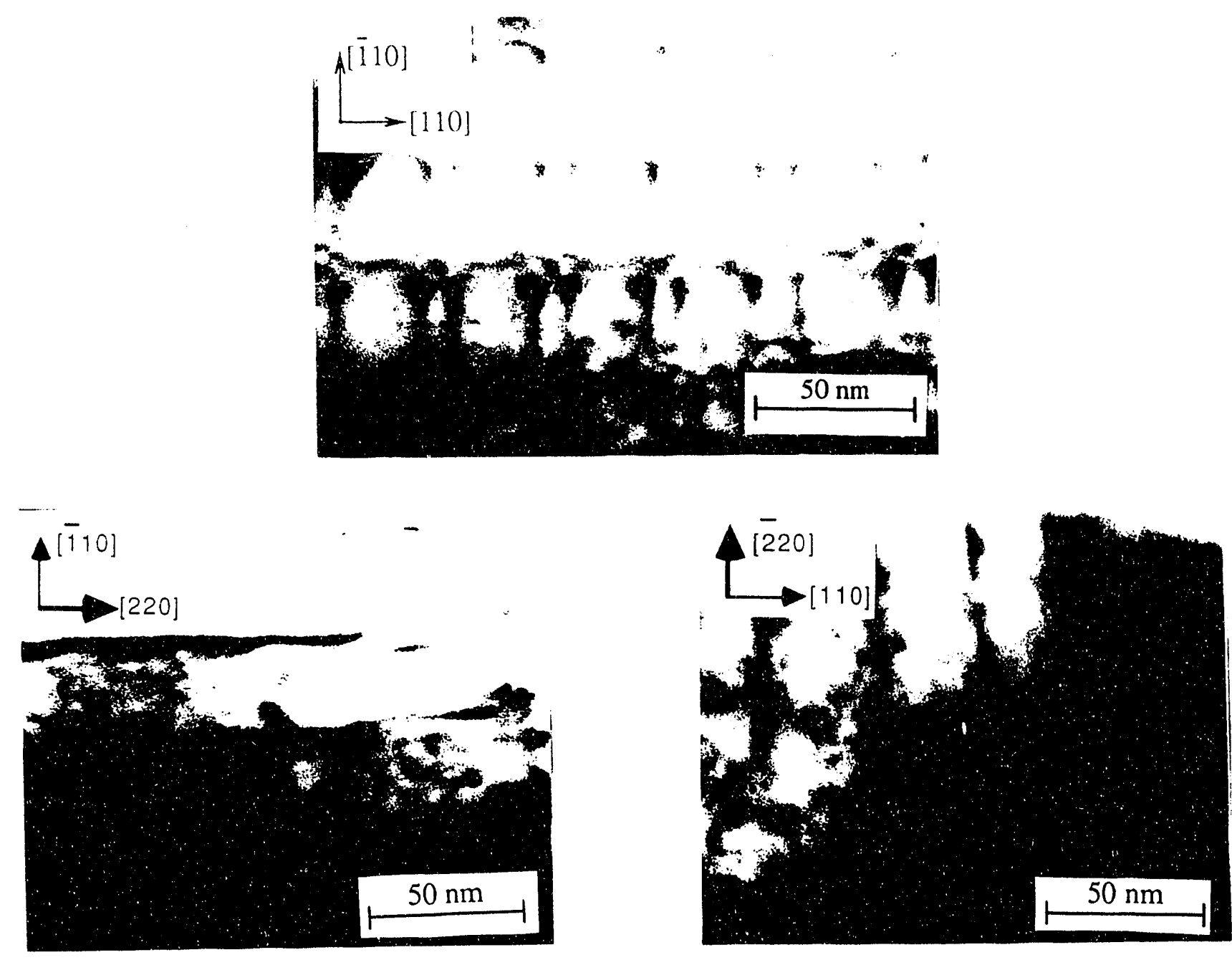

$$
\begin{gathered}
\theta=0.7^{\circ} \pm 0.1^{\circ} \quad \mathbf{d}=35.7 \mathrm{~nm} \\
\overrightarrow{\mathbf{b}}=\mathbf{a}<110> \\
\gamma_{25}{ }^{\circ} \mathrm{C}=60 \pm 13 \mathrm{~mJ} / \mathrm{m}^{2} \\
\gamma_{1000}{ }^{\circ} \mathrm{C}=43 \pm 9 \mathrm{~mJ} / \mathrm{m}^{2}
\end{gathered}
$$

Fig. 1 Electron microscopy observations or a small angle [001] twist boundary in boron-doped $\mathrm{Ni}_{3} \mathrm{Al}$. 
Table 1

$\mathrm{APB}$ energies in small angle [001] twist boundaries in $\mathrm{Ni}-24$ at. pct $\mathrm{Al}$

\begin{tabular}{|c|c|c|c|}
\hline & & $\begin{array}{c}\gamma_{001} \\
\left(\mathrm{~mJ} / \mathrm{m}^{2}\right)\end{array}$ & $\begin{array}{c}\gamma_{001} \\
\left(\mathrm{~mJ} / \mathrm{m}^{2}\right)\end{array}$ \\
\hline & Angle $\left(^{\circ}\right)$ & $1000^{\circ} \mathrm{C}$ & $25^{\circ} \mathrm{C}$ \\
\hline \multirow[t]{2}{*}{ B-free } & 0.0 & & $90 \pm 5^{3}$ \\
\hline & 1.1 & $50 \pm 10$ & $70 \pm 11$ \\
\hline \multirow[t]{4}{*}{ B-doped } & 0.0 & & $92^{4}$ \\
\hline & 0.7 & $43 \pm 9$ & $60 \pm 13$ \\
\hline & 1.6 & $5 \pm 3$ & $7 \pm 4$ \\
\hline & 2.0 & $7 \pm 2$ & $10 \pm 3$ \\
\hline
\end{tabular}

3 J. Douin et al (1986)

4 P. Veyssiere et al (1989)

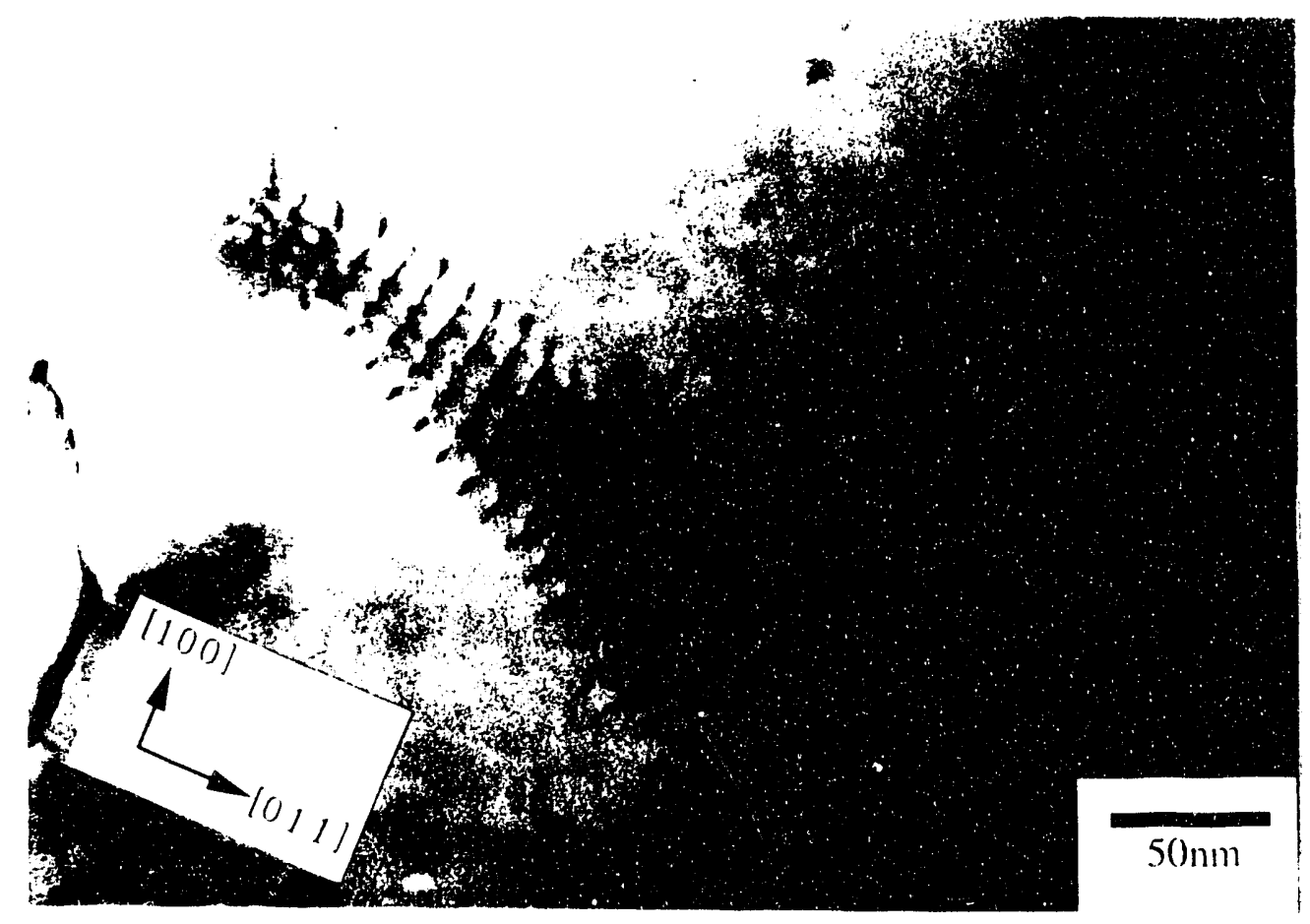

Fig. 2 Electron microscopy observations on a small angle [001] tilt boundary in boron-doped NiAl. $\theta=2^{\circ}$. Burgers vector is $a<110>$. 
the absence of pairing, and measurements of $\theta$ and the dislocation spacing giving a Burgers vector of $a<110>$, demonstrate that dissociation into partial dislocations does not occur. A similar tilt boundary in $\mathrm{Ni}_{3} \mathrm{Al}$ would exhibit dislocation dissociation.

\section{B. The Influence of Boron Additions on the Microstructure of Stoichiometric} NiAl (5)

$\mathrm{NiAl}$ has recently received considerable attention because of its potential for high temperature structural applications (6). Lack of ductility at low temperature is still its main drawback and restricts its use. While boron strengthens the boundaries (7) and suppresses intergranular fracture, the low temperature ductility is still not greatly improved (8). Recently, Jayaram and Miller (9) reported the presence of a low number density of $(\mathrm{Ti}, \mathrm{V}, \mathrm{Cr}) \mathrm{B}_{2}$ precipitates in stoichiometric boron-doped NiAl. These particles were suggested to increase the yield stress by precipitation hardening. As part of our research on the structure of grain boundaries in $\mathrm{NiAl}$, we have made observations that have helped to clarify the effect of boron on the structure and properties of this material.

Figure $3(\mathrm{a}, \mathrm{b})$ shows observations made on polycrystalline NiAl, where it is seen that when boron is present, small particles are also present. Figure $4(a, b)$ shows the results of an analytical electron microscopy study of the particles in Fig. 3, which demonstrate that they contain Ti, V, Cr, Mn and Fe. Figure 5 (a,b) shows observations on a boron-doped $\mathrm{NiAl}$ single crystal provided by General Electric. Figure 5 (a) shows the presence of large plates, while the X-ray spectra in Fig. 5 (b) demonstrate that these plates are Fe-rich.

Since these particles are only present in boron-doped $\mathrm{NiAl}$, it is likely that they are a boride compound, whose composition is determined by the trace impurities in the NiAl. As suggested by Liu (10), by careful control of the levels of impurities in the $\mathrm{NiAl}$, it should be possible to decrease the number of particles, and thereby lower the yield stress, and, in this manner, increase the ductility. 
(a)

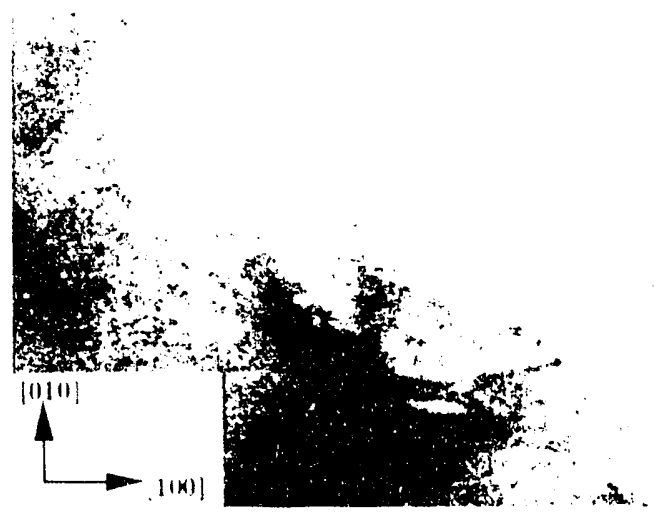

(b)

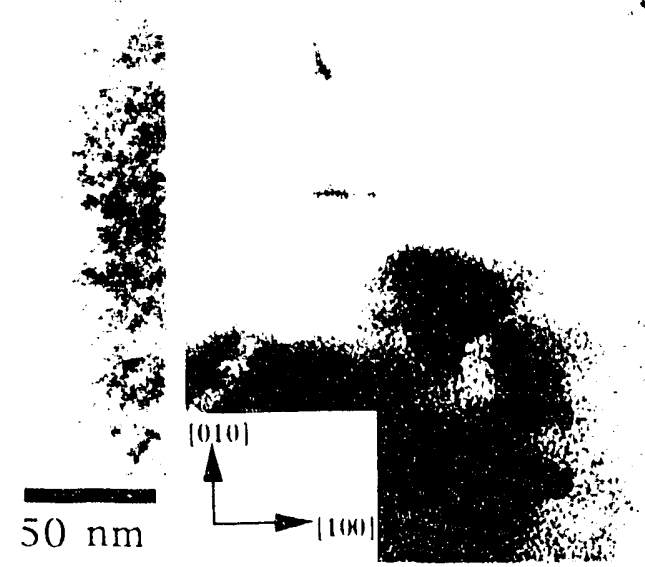

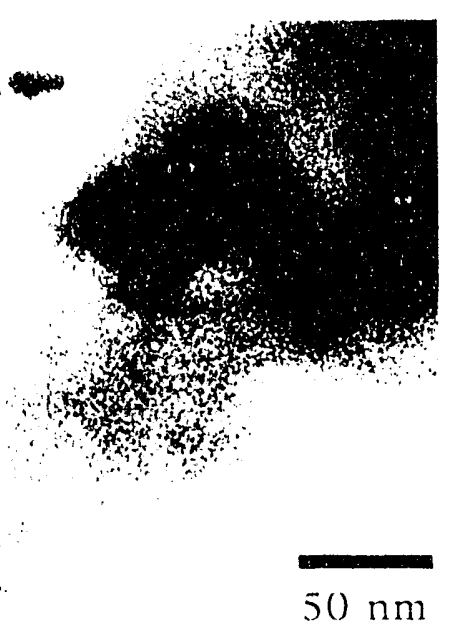

Fig. 3 Polycrystalline NiAl (a) Bright field image of boron-free NiAl, (b) Bright field image of boron-doped NiAl.

(a)

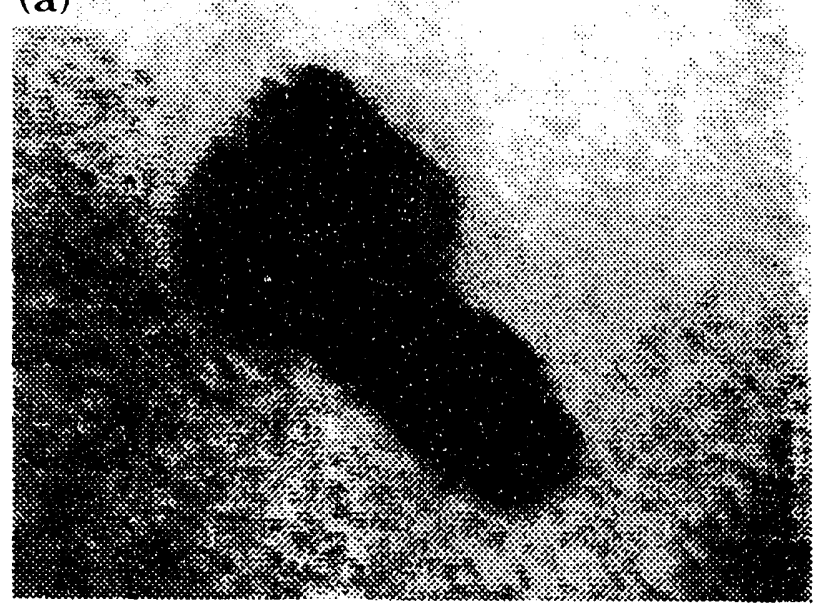

(b)

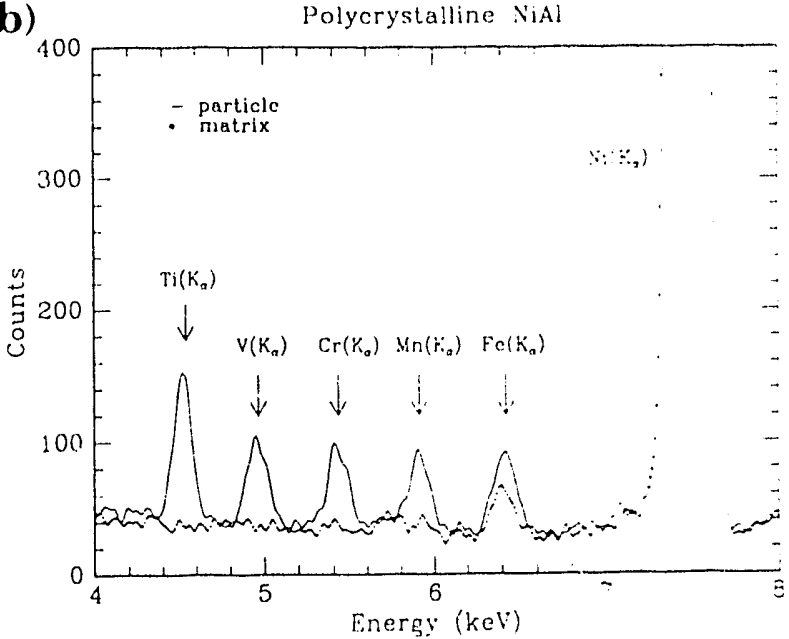

Fig. 4 (a) Bright field image of particle in polycrystalline $\mathrm{NiAl}$ containing boron, examined by analytical electron microscopy, (b) X-ray spectra from the particle and the nearby matrix.
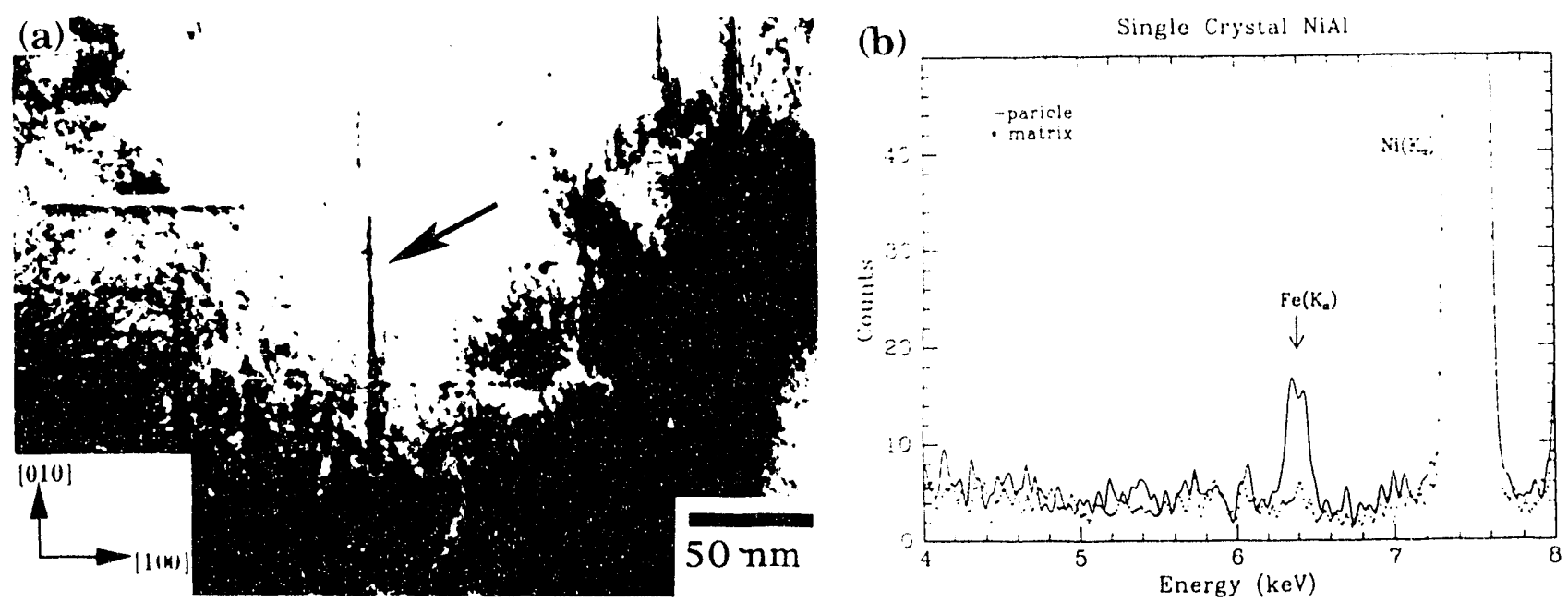

Fig. 5 (a) Bright field image of particle in single crystalline NiAl containing boron. (b) X-ray spectra from a particle and its nearby matrix. 


\section{The Influence of Solute-Induced Changes in the Structure of Grain Boundaries on their Mechanical Properties}

Past work on this grant (11-14) on the influence of solute segregation on boundary structure in Fe demonstrated that, in the presence of solute, dislocations with Burgers vector of the type $a<100>$ are favored relative to those with Burgers vector of the type $a / 2<111>$. It was not known from this work, however, if the boundaries containing a $<100>$ dislocations were any more brittle than those containing $a / 2<111>$ dislocations. Cottrell (15), Sleeswyk and Mandziej (16), and Mandziej (17) have discussed the role of a<100>-type dislocations in the nucleation of cleavage cracks in b.c.c. metals. Cottrell suggested that the reaction of two $a / 2<111>$ dislocations can produce an $a<100>$ edge dislocation which acts as the nucleus of a crack. Munroe and Baker (18) reported experimental evidence in support of this model in $\mathrm{FeAl}$ alloys with the $\mathrm{B} 2$ structure. Since the dislocations stabilized by solute segregation in small angle boundaries in $\mathrm{Fe}$ also have an a $<100>$ Burgers vector, it was decided to determine whether they play a role in initiating grain boundary fracture.

To link our observations on grain boundary dislocations to the mechanical properties of the same boundaries, it is necessary to carry out mechanical properties measurements on bicrystals. The dislocation studies were carried out using Fe bicrystals obtained by hot pressing together thin single crystals of $\mathrm{Fe}$ produced by epitaxial growth. These specimens are too thin to be useful for mechanical testing.

Specimens suitable for mechanical properties studies are being produced in the following manner. Large single crystals of b.c.c. Fe are being grown by the strain-anneal method in the Cornell Materials Science Center Materials Preparation Facility. Half inch diameter rods of electrolytic Fe are zone-refined to remove impurities, doped with $50 \mathrm{ppm} \mathrm{C}$, swaged and annealed to produce a fine grain size, then deformed between 1 to $3 \%$, and finally slowly dropped through a furnace at a temperature just beneath $910^{\circ} \mathrm{C}$. Single crystals of a suitable size 
(Fig. 6) are oriented using Laue techniques and then cut to obtain flat (001) surfaces. After careful polishing, two such crystals are misoriented by a few degrees about their common [001] direction and then hot pressed together under a hydrogen atmosphere to produce small angle [001] twist boundaries, using the conditions established by Sickafus and Sass (11). Figure 7 shows an early attempt at the production of macroscopic bicrystals.

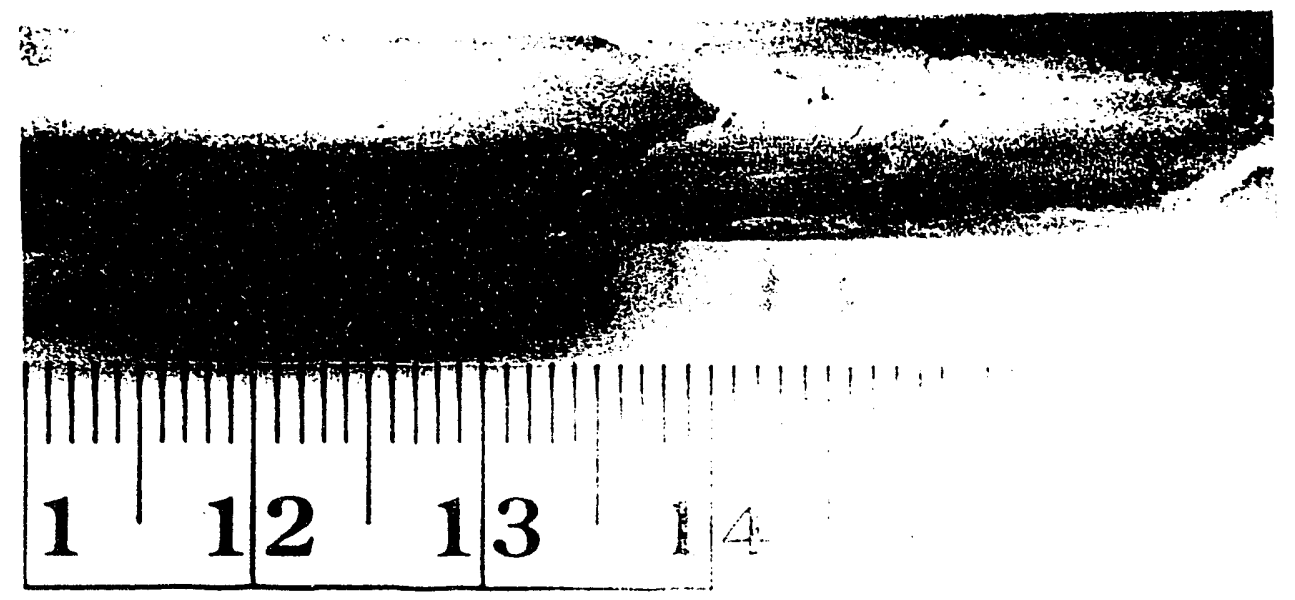

Fig. 6 Ilustrating large Fe single crystals produced by the strain-anneal method.

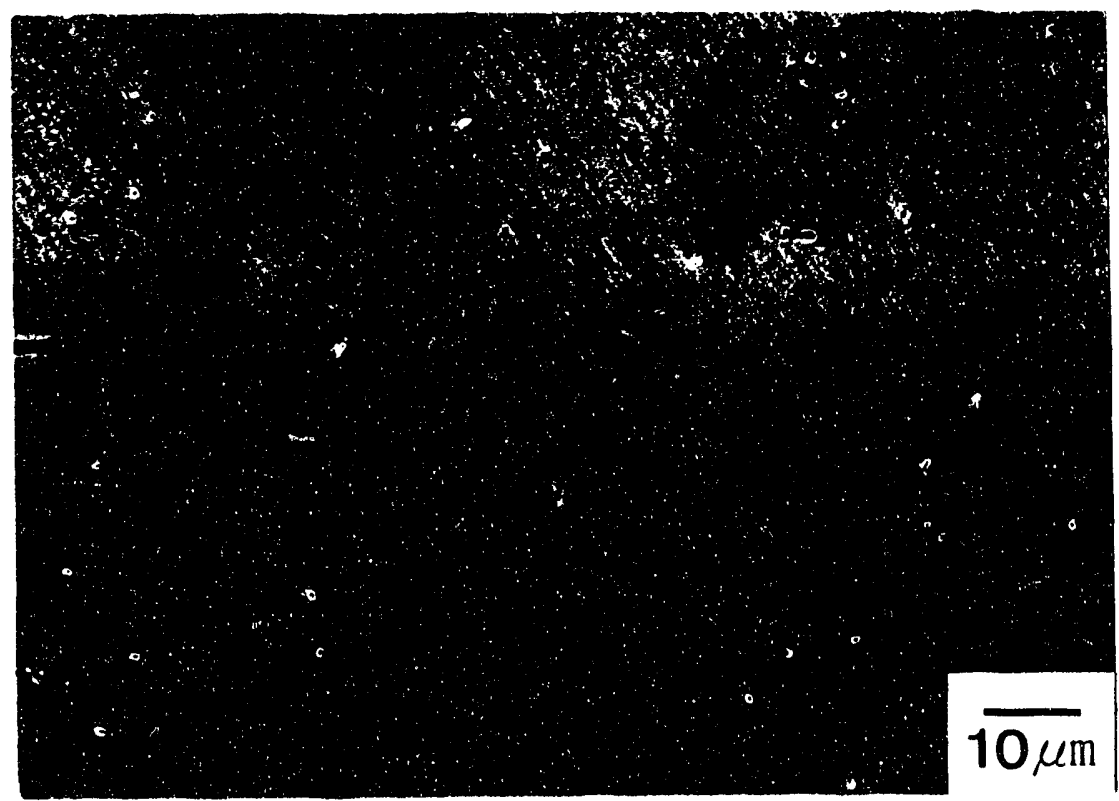

Fig. 7. Macroscopic Fe bicrystal formed by hot pressing at $600^{\circ} \mathrm{C}$ in a hydrogen atmosphere under $30 \mathrm{MPa}$. 


\section{References}

1. H. Kung, D. R. Rasmussen and S. L. Sass, Acta Met. 40, 81 (1992)

2. H. Kung and S. L. Sass, Acta Met. 40,99 (1992)

3. J. Douin, P. Veyssière and P. Beauchamp, Phil. Mag. A54, 375 (1986)

4. P. Veyssière, M. H. Yoo, J. A. Horton and C. T. Liu, Phil. Mag. Let., 59, 61 (1989)

5. T.-S. Wu and S. L. Sass, Scripta Met. To be published (1993)

6. R. Darolia, JOM 3, 44 (1991)

7. E. P. George and C. T. Liu, J. Mater. Res. 5, 754 (1990)

8. E. P. George and C. T. Liu and J. J. Liao, MRS Symp. Proc. 186, 1990

9. R. Jayaram and M. K. Miller, Surf. Sci. 266, 310 (1992) MRS Symp. Proc. 239, 445 (1992)

10. C. T. Liu, Private communication

11. K. Sickafus and S. L. Sass, Scripta Met.18, 165 (1984)

12. K. E. Sickafus and S. L. Sass, Acta Met.35, 69 (1987)

13. C.-H. Lin and S. L. Sass, Scripta Met. $\underline{22}, 735$ (1988)

14. C.-H. Lin and S. L. Sass, Scripta Met. 22, 1569 (1988)

15. A. H. Cottrell, Trans. AIME 212, 192 (1958)

16. A. W. Sleeswyk and S. Mandziej, Scripta Met. 24, 7 (1990)

17. S. Mandziej, Scripta Met. 25, 213 (1991)

18. P. R. Munroe and I. Baker, Acta Met. 39, 1011 (1991) 


\section{S. L. Sass Publication List on this Grant - 1992-3}

1. "Grain Boundaries in $\mathrm{Ni}_{3} \mathrm{Al}$, Part I: The Local Compositional Order", $\mathrm{H}$. Kung, D. R. Rasmussen and S. L. Sass, Acta Met. 40, 99 (1992)

2. "Grain Boundaries in $\mathrm{Ni}_{3} \mathrm{Al}$, Part II: The Dislocation Structure of Small Angle Boundaries", H. Kung and S. L. Sass, Acta Met. 40, 81 (1992)

3. "The Local Compositional Order and Dislocation Structure of Grain Boundaries in $\mathrm{Ni}_{3} \mathrm{Al}^{\prime}, \mathrm{H}$. Kung, D. R. Rasmussen and S. L. Sass, Ordered Intermetallics - Physical Metallurgy and Mechanical Behaviour, C. T. Liu et al (eds.), Kluwer Academic Publishers., p. 355 (1992)

4. "The Dislocation Structure of Large Angle [001] Twist Boundaries in b.c.c. Iron", C.-H. Lin and S. L. Sass, Scripta Met. 26, 1055 (1992)

5. "Deformation and Fracture of Intermetallics", M. H. Yoo, S. L. Sass, C. L. Fu, M. J. Mills, D. M. Dimiduk and E. P. George, Acta Met. 41, 987 (1993)

6. "Electron Microscopy Observations on the Influence of Boron Additions on Stoichiometric NiAl", T.-C. Wu and S. L. Sass, MRS Proceedings (1992)

7. "The Influence of Boron Additions on the Microstructure of Stoichiometric NiAl", Scripta Met. To be published (1993) T.-S. Wu and S. L. Sass

\section{List of Personnel 1992-93}

Graduate Research Assistants

Shanthi Subramanian

Alice $\mathrm{Wu}$

Zhenjun Zhang
Expected Completion Date

June 1996

June 1995

June 1996 

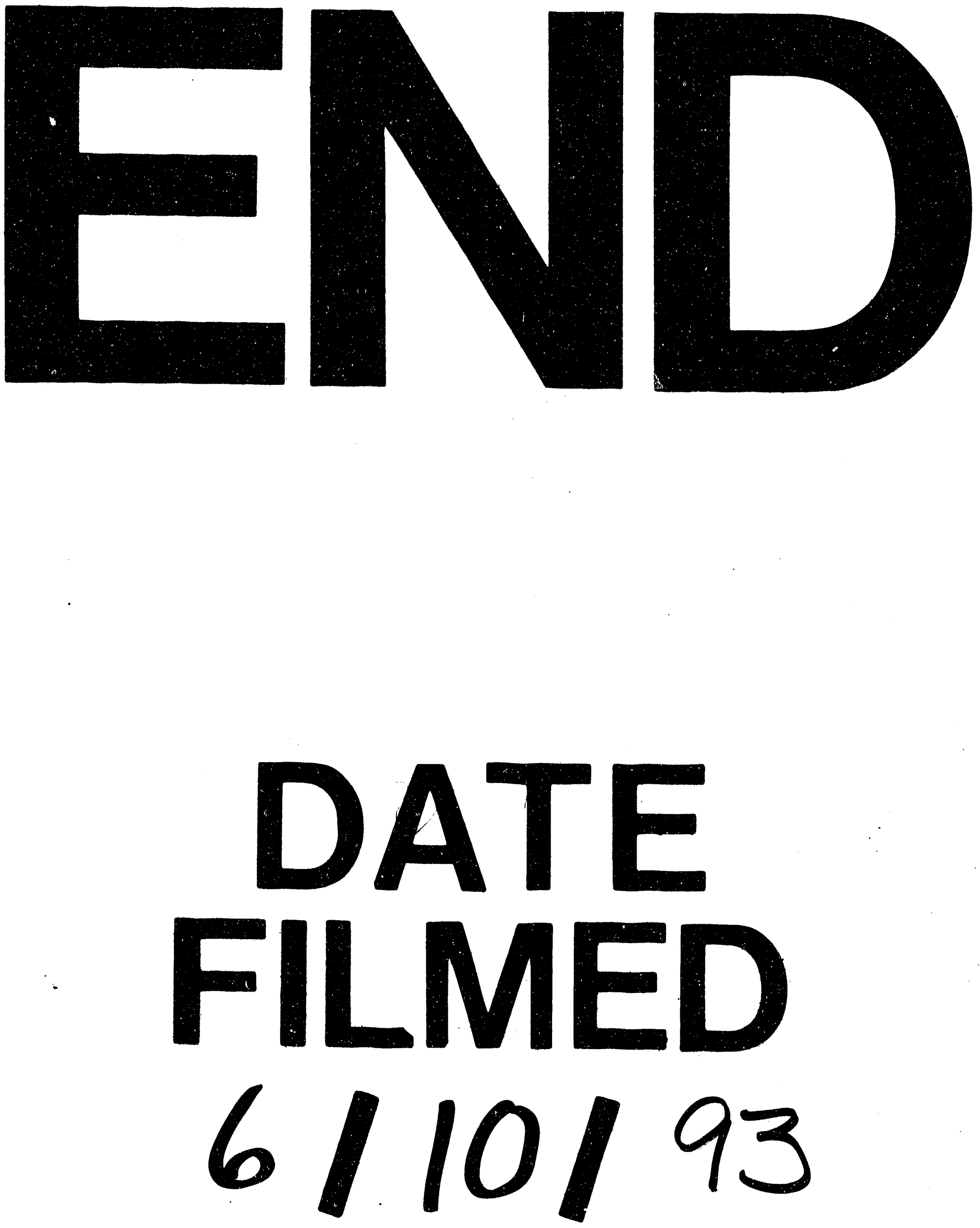
